\title{
Déjà vu on climate change
}

\author{
The latest report on global warming brings yet another rise in confidence that human actions are altering \\ the Earth's climate. But in contrast to its 2007 predecessor, it is unlikely to cause a stir.
}

Readers of the fifth assessment report from the Intergovernmental Panel on Climate Change (IPCC) may well feel that they have seen much of it before. The report from Working Group I is due for final approval and publication just before this Editorial is published. However, earlier drafts have been widely reported, following leaks during the lengthy period of assemblage, review and re-review. Perhaps more importantly, many of the key quantifications of change have stubbornly remained within very similar uncertainty ranges over the set of five assessment reports since 1990. Sea level is now projected to rise by between 0.29 and 0.96 metres by the year 2100 , compared to a range of about 0.32 to 1.08 metres in the 1990 report. And with a range of 1.5 to $4.5^{\circ} \mathrm{C}$, projections of the response of global mean temperatures to a doubling of atmospheric carbon dioxide concentrations have arrived back where they started in the first report, after some minor ups and downs on both boundaries over the course of the five reports.

This is not to say that there has been no progress. Cloud feedbacks, an issue of long-standing debate over the years, are now assessed as likely to be positive overall. Patterns of projected precipitation change, another conundrum, are emerging with high confidence: more rain and snow is expected in high latitudes, whereas the more arid regions in mid-latitudes will probably dry out further. It is also important to keep in mind that the number ranges given in the first report were based on very patchy knowledge and could quite plausibly have been overturned by further work. The fact that they have stood the test of time may be testimony to the excellent intuition of the 1990 IPCC authors - or just pure luck. In any case, thanks to almost two and a half decades of intensive work, we now know that the climate is warming, and confidence that we understand the most important causes, feedbacks and impacts of this warming is immeasurably higher.

In 1990, the relative magnitudes of human-induced warming and natural variability were quite unclear, and unequivocal detection of the effect of human action on climate was considered "not likely for another decade or more" (http://go.nature.com/VYJMxK). According to the draft version of the 2013 report that

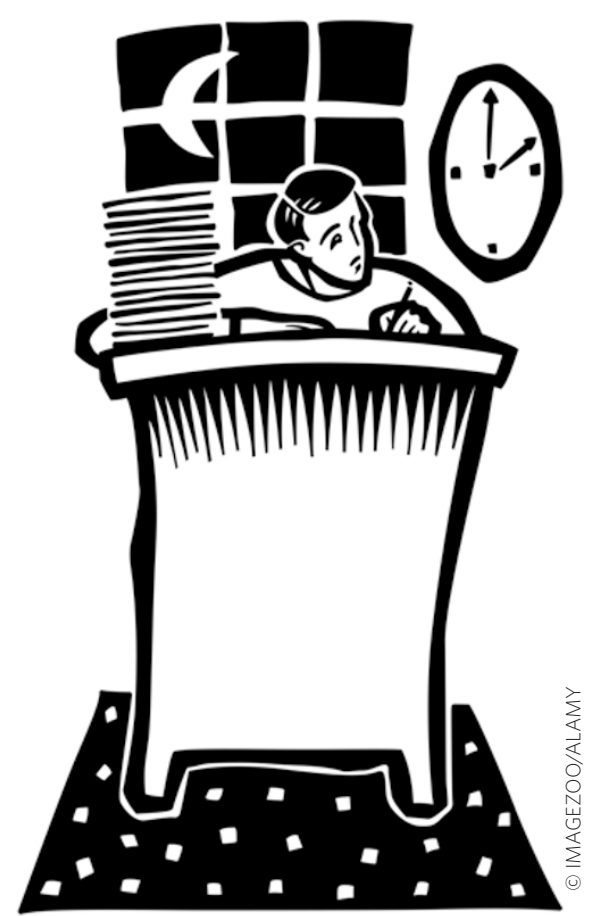

Authors of the IPCC report spend long hours assessing the literature.

was available at the time of writing, "it is extremely likely that human activities have caused more than half of the observed increase in global average surface temperature since the 1950s". That is still weaker than unequivocal detection, but room for doubt is clearly dwindling: "extremely likely" in IPCC terminology translates to a probability of more than 95\%.

A much higher degree of certainty is probably not achievable. After all, the report is a consensus document that encompasses the interpretations, by a large and diverse community of scientists, of incomplete and imperfect measurements and projections of the Earth's climate. The IPCC process is thus facing diminishing returns. The lower-limit probability given for the statement that most of the recent warming was human-induced evolved from $66 \%$ in 2001 to $90 \%$ in 2007 , and now 95\% in 2013.

The two big questions for which the IPCC was founded (is the planet's climate changing, and, if so, are humans responsible) had effectively been answered, in the affirmative, in 2007. The emerging narrative from this latest report, of an incremental consolidation of 23-year-old climate change projections for the twenty-first century, is unlikely to energize the public into demanding more decisive climate change mitigation from their political representatives, let alone changing their own way of life.

Climate scientists, by contrast, are energized enormously by the IPCC process, albeit some time before the publication of each report. Most noticeable from our perspective, in the run-up to the submission deadline for manuscripts to be considered in the report, Nature Geoscience received an unprecedented number of papers (Nature Geosci. 6, 1; 2013) - although only a fraction of the subjects we cover is relevant to the IPCC report now published. Not all of those additional papers were as carefully thought through as might be desirable: like everyone else, climate researchers respond to the pressure of deadlines. Evaluating this immense body of last-minute work, along with all the other studies published since the previous assessment in 2007, has bound vast amounts of climate scientists' time.

Such an enormous collective effort requires compelling justification, especially now that the reality and primary cause of climate change are essentially settled. As the community is facing a larger number of second-tier questions - for example, regarding the manifestation of climate change in extreme events, in water and food availability and on regional scales, or the ever-elusive effect of aerosols on climate a less monolithic approach may well be more efficient.

In our January 2013 issue, Thomas Stocker, co-chair of Working Group I of the IPCC, suggested that future IPCC work could be split into a series of assessments - for example, along the lines of the current chapter structure, each updated individually at the pace of the relevant science (Nature Geosci. $6,7-8 ; 2013)$. Such a procedure would be in line with good practice for scientific publications: write a paper only when there is something new to report.

Before another round of assessments starts, we need a catalogue of the most pressing, second-tier open problems. When a new consensus forms on any of those - and perhaps only then - a focussed report on that issue would be due. 